commercial application. A Sunday supplement article pictured a housewife opening a small closet off the kitchen and picking tomatoes from vines growing in water culture with the aid of electric lights, whilst a large chain of restaurants in New York City were credited with growing their own vegetables in basements. Actually, as the authors of this circular make clear, whilst very good yields may be obtained under glass from many crops grown in water cultures, with cqual attention, similar or better crops may be grown in soil by methods which are more familiar to the amateur and professional grower.

\section{Foam on the Dead Sea}

A PECuliar phenomenon often to be seen on the northern waters of the Dead Sea is that of ares of foam, more or less semicircular, spreading out fanwise from certain points of the west and east shores. The arcs seem to spread from the shores in early morning and often meet and even cross during the forenoon. These lines of foam often bear reeds and other vegetation debris that have reached the Dead Sea by inflowing rivers, and, at the seasons of migration, the foam may attract flocks of birds searching for food. Dr. D. Ashbel has recorded some of his observations on this phenomenon and offers an explanation (Geog. Rev., Jan. 1938). The ares originate from springs on the two shores, and they make discontinuities between bodies of water of different salinity and density. When the outflow of the springs is strong, the arc is frequently not smooth but zig-zag. This explanation contradicts the earlier one of Blanckenhorn that the lines of foam originate from warm water arising along lines of fault on the sea floor. That suggestion does not explain lack of replaccment of the lines as each moves forward, which Dr. Ashbel thinks is due to the gentle winds that frequently blow from the land on to the sea during the night and early morning. These winds do not ruffle the water and so mixing does not occur. Gusty west winds such as often occur in the afternoon cause mixing and so the lines of discontinuity disappear.

\section{The Imperial College of Tropical Agriculture}

THE Imperial College of Tropical Agriculture in Trinidad is now the recognized centre for postgraduate training in tropical agriculture for the agricultural services of the Colonial Empire. The governing body in its latest report for the year encling August 31, 1938, record that 159 past students of the College have been appointed to the Colonial Agricultural Service and allied services, posts being now held in thirty different parts of tho British Empire. The year under review was marked by the retirement of Sir Geoffrey Evans, who had filled the office of principal with much distinction since 1926 , and who left the College with its function in the development of agriculture throughout the Colonial Empire firmly established, and with an international reputation as a centre of education and research. Mr. Odin T'om Faulkner, lately director of agriculture in the Straits Settlements and adviser on agriculture in the Malay States, was appointed to succeed Sir Geoffrey Fvans. During 1937-38 the work of the College proceeded on normal lines. Research was mainly concerned with problems relating to cacao, sugar, bananas and citrus fruits, and the cost of much of the work was met by contributions from firms connected with the appropriate industry. The governing body is anxious to raise a substantial endowment fund; but its hope that the grant of $£ 32,000$ made by the Carnegie Corporation in 1932 towards this object would b'e followed by contributions from British firms and others interested in tropical agriculture has yet to be realized. Capital is also required for the purchase of more land for the college farm, for additional laboratories and tho reconstruction of the biological building.

\section{The British Association: Engineering Section}

AT the Dundee meeting of the British Association, 1939, the Engineering Section proposes to repeat the arrangement which proved so satisfactory during the meeting in Cambridge last year and to devote some time to the delivery of a number of short communications by junior engineers or research workers (under the age of thirty years). Each speaker will be allotted a total of 20-30 minutes, which may, at his option, include, say, ten minutes for very short discussion. It is hoped that each author will describe some item of special interest or novelty upon which he may be engaged. This innovation seems to us important as cnabling the Association to know something of the work of younger men, and enabling those men to gain experience of summarizing their work and putting it forward for criticism without having to undertake the much more laborious task of preparing a paper of the stature nocessary for a full mecting of one of the engineering institutions or of a scientific society. Although Engineering publishes in extenso the text of all main papers delivered to the Scction, it is not proposed that these short papers should similarly be published. This arrangement seems desirable, partly because authors may be prepared to describe engineoring work upon which they hope later to publish a full-scale paper, and partly because authors may not feel justified in preparing a text of the completeness which would be desirable if propor publication is to bo made. Thoso wishing to submit such papers should communicate immediately with the recorder Wing-Commander T. R. Cave-Brown-Cave, University College, Southampton.

\section{Spectrochimica Acta}

THe first number of a publication under the above titlo will shortly be issued by Messrs. Julius Springer, Berlin, under the editorship of W. Gerlach and G. Scheibe, Munich ; A. Gatterer, Vatican Observatory ; R. Breckpot, Louvain; F. Twyman, London. It will deal solely with spectrochemical analysis, and a useful feature will be the publication of abstracts and roviews of books and articles on the subject. A number of authorities on the subject have agreed to collaborate, and those in the English-speaking 